\title{
Transcriptional profiling of reproductive development, lipid storage and molting throughout the last juvenile stage of the marine copepod Calanus finmarchicus
}

\author{
Ann M Tarrant ${ }^{1 *+}$, Mark F Baumgartner ${ }^{1 \dagger}$, Bjørn Henrik Hansen², Dag Altin ${ }^{3}$, Trond Nordtug ${ }^{2}$ and Anders J Olsen ${ }^{4}$
}

\begin{abstract}
Introduction: Calanus finmarchicus, a highly abundant copepod that is an important primary consumer in North Atlantic ecosystems, has a flexible life history in which copepods in the last juvenile developmental stage (fifth copepodid, (5) may either delay maturation and enter diapause or molt directly into adults. The factors that regulate this developmental plasticity are poorly understood, and few tools have been developed to assess the physiological condition of individual copepods.

Results: We sampled a cultured population of $C$. finmarchicus copepods daily throughout the $C 5$ stage and assessed molt stage progression, gonad development and lipid storage. We used high-throughput sequencing to identify genes that were differentially expressed during progression through the molt stage and then used qPCR to profile daily expression of individual genes. Based on expression profiles of twelve genes, samples were statistically clustered into three groups: (1) an early period occurring prior to separation of the cuticle from the epidermis (apolysis) when expression of genes associated with lipid synthesis and transport (FABP and ELOV) and two nuclear receptors (ERR and HR78) was highest, (2) a middle period of rapid change in both gene expression and physiological condition, including local minima and maxima in several nuclear receptors (FTZ-F1, HR38b, and $E(R)$, and (3) a late period when gonads were differentiated and expression of genes associated with molting (Torso-like, HR38a) peaked. The ratio of Torso-like to HR38b strongly differentiated the early and late groups.

Conclusions: This study provides the first dynamic profiles of gene expression anchored with morphological markers of lipid accumulation, development and gonad maturation throughout a copepod molt cycle. Transcriptomic profiling revealed significant changes over the molt cycle in genes with presumed roles in lipid synthesis, molt regulation and gonad development, suggestive of a coupling of these processes in Calanus finmarchicus. Finally, we identified gene expression profiles that strongly differentiate between early and late development within the C5 copepodid stage. We anticipate that these findings and continued development of robust gene expression biomarkers that distinguish between diapause preparation and continuous development will ultimately enable novel studies of the intrinsic and extrinsic factors that govern diapause initiation in Calanus finmarchicus.
\end{abstract}

Keywords: Arthropod, Crustacean, Gene expression, Molt cycle, Transcriptomics

\footnotetext{
*Correspondence: atarrant@whoi.edu

'Equal contributors

'Biology Department, Woods Hole Oceanographic Institution, 45 Water

Street, Woods Hole, MA 02543, USA

Full list of author information is available at the end of the article
}

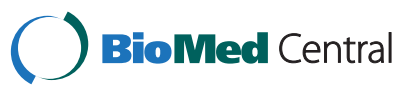

(C) 2014 Tarrant et al.; licensee BioMed Central. This is an Open Access article distributed under the terms of the Creative Commons Attribution License (http://creativecommons.org/licenses/by/4.0), which permits unrestricted use, distribution, and reproduction in any medium, provided the original work is properly credited. The Creative Commons Public Domain Dedication waiver (http://creativecommons.org/publicdomain/zero/1.0/) applies to the data made available in this article, unless otherwise stated. 


\section{Introduction}

Copepods of the family Calanidae, including the Calanus and Neocalanus genera, are vital components of temperate, subarctic, and arctic ecosystems that transfer energy directly from phytoplankton to very high trophic levels (e.g., fish, sea birds, and some marine mammals). The life history of these copepods typically includes diapause, a period of arrested development, dormancy and fasting that can last many months [1-3]. The well-studied temperate and subarctic copepod, Calanus finmarchicus, prepares for diapause primarily during the fifth and final juvenile stage (C5). However, C. finmarchicus is not obligated to enter diapause, and some individuals skip diapause, molt immediately into adults, and become reproductively mature. Despite their ecological importance, strikingly little is known about developmental regulation in $C$. finmarchicus or other members of the family Calanidae. Diapause physiology is difficult to study directly in Calanus spp. because researchers cannot reliably induce the diapause state under laboratory conditions. Thus, we are currently ignorant of the intrinsic and extrinsic factors that influence the "choice" to enter diapause or to molt directly into adulthood in $C$. finmarchicus, and this ignorance limits our ability to predict population dynamics beyond a single generation.

Calanus finmarchicus undergoes dramatic physiological changes during the C5 copepodid stage (Figure 1). The most noticeable of these changes is the accumulation of lipids in an organ called the oil sac. The lipids stored in the oil sac are almost entirely wax esters; much smaller

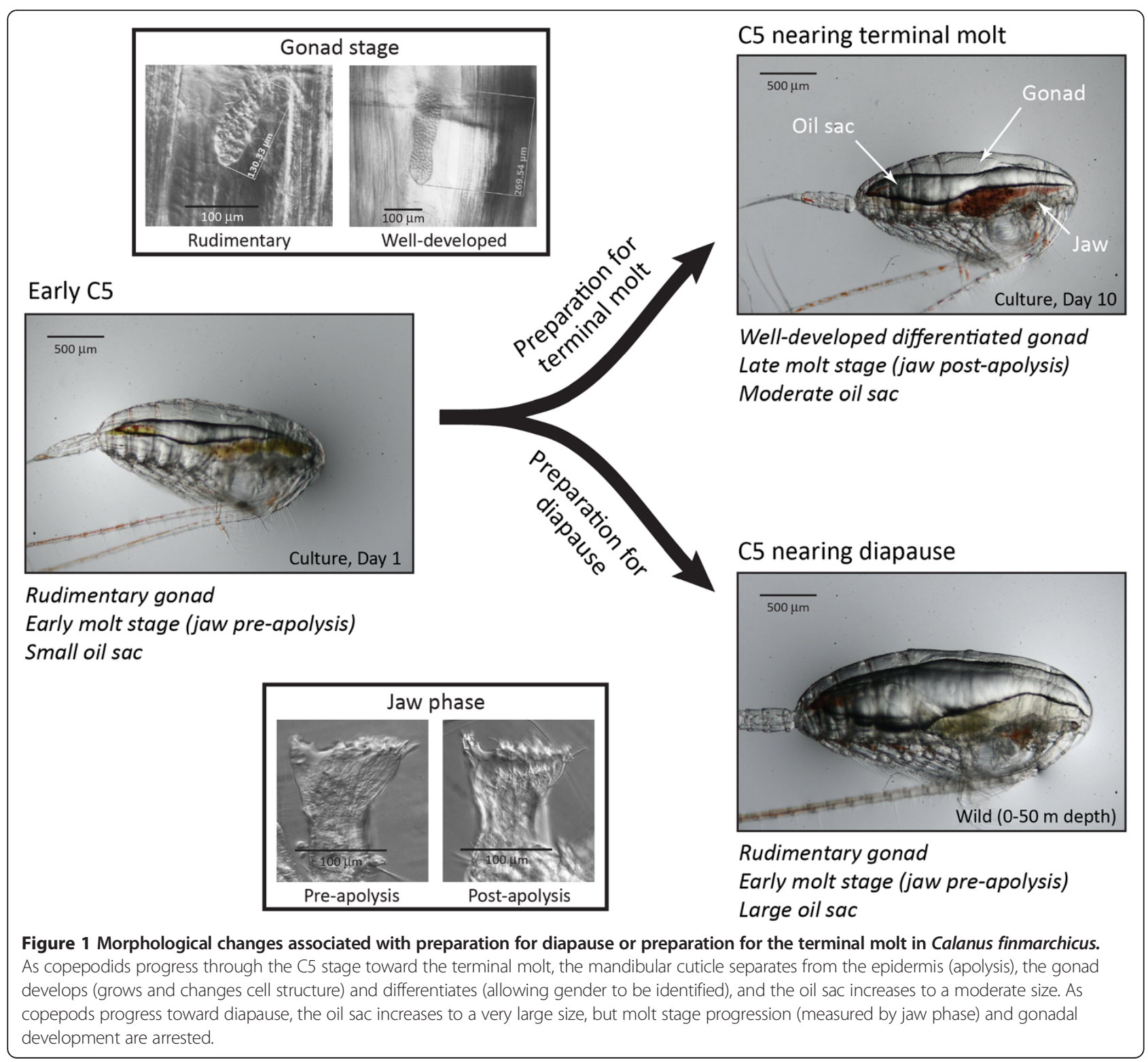


amounts of triglycerides and phospholipids are stored in lipid droplets throughout the body [4]. Lipids accumulated in the oil sac will later be metabolized during fasting by diapausing copepodids, and/or utilized during molting and gonad maturation [5,6], oogenesis [7], or locomotion [8] by adult copepods. The oil sac volume, which can be estimated from analysis of photographs [9], is positively correlated with total lipid content in C. finmarchicus C5 copepodids [4]. Gonads appear during the C4 stage [10], but reproductive development accelerates during the C5 stage in copepodids preparing for the terminal molt [7]. Progression toward ecdysis (molting) can be monitored through changes in the mandibular gnathobase during tooth formation [11]; in particular, separation of the cuticle from the epidermis, a processes called apolysis, is a key transition within the arthropod molt cycle that can be detected first in the copepod mandibular gnathobase.

While little is known about regulation of copepod molting, extensive studies in other arthropods (mainly insects and decapods) have shown that molting is regulated by a cascade of hormonal signals (reviewed by $[12,13]$ ). Binding of ecdysteroids activates the ecdysone receptor (EcR), which is a member of the nuclear receptor superfamily. EcR forms a complex with another nuclear receptor, the retinoid-x-receptor (RXR) to regulate the transcription of target genes, including several other nuclear receptors (reviewed by [13]). Many studies have characterized EcR and RXR expression during crustacean molt cycles [14-16]; however, few studies have documented expression patterns of other nuclear receptors [17]. While ecdysteroid signaling has not been extensively studied in copepods, Johnson [18] and Hansen et al. [19] found dynamic patterns of ecdysteroid concentration in C5 copepodids from Calanus spp. Expression of EcR and other nuclear receptors has not been studied across the molt stage of any copepod, but results from field studies of $C$. finmarchicus are consistent with increased EcR expression in preparation for emergence and molting late in diapause [20,21].

Ontogenetic changes in morphology are often accompanied or even preceded by changes in gene expression, and characterizing these gene expression patterns can help elucidate underlying developmental processes. A few studies have described gene expression patterns associated with progression through the crustacean molt cycle. Genes exhibiting dynamic expression patterns include cuticular proteins [22,23] and nuclear receptors [17]. In C. finmarchius, Tarrant et al. [20] suggested that expression of genes associated with lipid synthesis, transport and storage is correlated with lipid accumulation during the C5 stage. Recent studies have employed high-throughput sequencing (RNA-seq) to compare expression among crustacean developmental stages (e.g., [24,25]). Lenz et al. [26] described a de novo transcriptome assembled across the entire $C$. finmarchicus developmental cycle (embryos to adults) from which gene expression patterns associated with circadian and peptidergic signaling have been investigated $[27,28]$; however, these studies have focused on comparisons between developmental stages. To gain insight into diapause and maturation processes that happen at the end of juvenile development in C. finmarchicus, it is necessary to compare transcriptional profiles within the C5 stage.

In this paper, we characterize transcriptional profiles associated with progression through the final copepodid stage of C. finmarchicus during preparation for the terminal molt. Our goals were to (1) identify genes associated with lipid storage, reproductive development, and ecdysis during preparation for the terminal molt, (2) characterize changes in the expression of those genes throughout the C5 copepodid stage at high temporal resolution, and (3) understand better the processes and pathways associated with maturation. Our long-term goals are to identify genes associated specifically with preparation for diapause, and to develop markers that can be used to distinguish $\mathrm{C} 5$ copepodids that are preparing for the terminal molt and for diapause. With robust molecular markers of these two developmental pathways, new studies can be designed to investigate the factors that influence the "choice" to proceed directly to the terminal molt or to enter diapause. Here, we address the first of these developmental pathways with a transcriptional profiling study of laboratory-reared copepods that are preparing for the terminal molt.

\section{Results}

Morphometrics, jaw phase, gonads, and stage duration Calanus finmarchicus C5 copepodids were sampled from a continuous laboratory culture daily at known times since the C4-C5 (penultimate) molt. Adults first appeared in this time series study 9 days after the penultimate molt, but $\mathrm{C} 5$ copepodids were still present on day 18 (Figure 2a). Median C5 stage duration was 13.5 days. Of the 173 copepods that molted into adults during the time series study, $44(25.4 \%)$ were male. In a small sample of $C 4$ copepodids collected prior to the penultimate molt $(\mathrm{n}=12)$, all but one had observable gonads. Of these, 4 had rudimentary gonads, 5 had developing gonads, and 2 were already differentiated (i.e., gender could be determined from welldeveloped gonads). Not surprisingly then, differentiated gonads were present early in the C5 stage; on nearly all sample days (except days 1 and 5), the majority of C5 copepodids had differentiated gonads (Figure 2b). Of the 98 C5 copepodids sampled with differentiated gonads during the time series study, 44 (44.9\%) had developing testes. Apolysis was first observed on day 6, but the percentage of post-apolysis copepodids did not increase monotonically thereafter (Figure 2b), suggesting that the timing of molt stage progression (i.e., within-stage development) is highly variable among individuals. A portion of the 

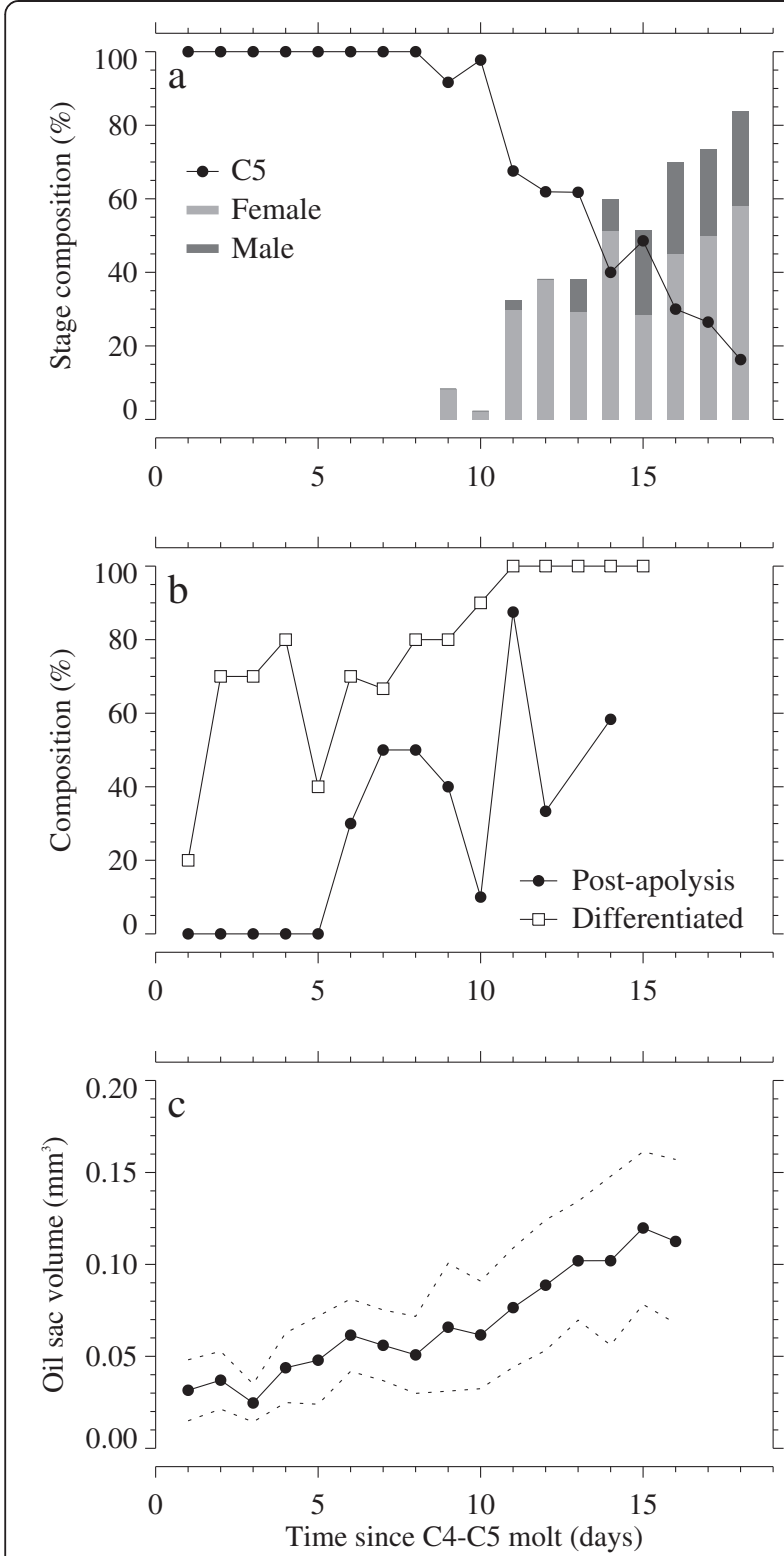

Figure 2 Time series of developmental stage composition, jaw phase, gonad stage, and oil sac volume. (a) Daily percentage of Calanus finmarchicus C5 copepodids (filled circles) and adults (gray bars) during the time series study ( $n=34-44$ copepods sampled per day). (b) Daily percentage of C5 copepodids with post-apolysis jaw phases (filled circles; $n=8-10$ for days $1-12$, days $13-15$ combined since $n=4$ on each of those days, $n=0$ for days $16-18$ ) and differentiated gonads (open squares; $n=8-10$ for days $1-13, n=4$ for days $14-15$, $\mathrm{n}=0$ for days 16-18). (c) Average (filled circles) and standard deviation (dotted lines) of oil sac volume for sampled C5 copepodids ( $n=33-43$ for days $1-10, n=12-26$ for days $11-16$; days $17-18$ not plotted since $n<10)$.

variability near the end of the time series was attributable to our including only $\mathrm{C} 5$ copepodids in Figure 2b; had we included all individuals that underwent apolysis ( $\mathrm{C} 5$ and adults), the proportion of post-apolysis C. finmarchicus after day 10 would have been higher. In contrast to the variability observed in molt stage progression, average oil sac volume increased steadily 4-fold from day 1 to 16 (Figure 2c).

\section{Transcriptome assembly}

A single library was created from pooled RNA obtained from C. finmarchicus C5 copepodids. Illumina-based sequencing produced 93 million 100-bp paired-end reads. After quality trimming, 82.3 million paired-end reads and 10 million unpaired left reads were retained and assembled. The assembled transcriptome contained 124,157 Trinity components and 241,140 Trinity transcripts; multiple transcripts were frequently associated with a single component. The mean transcript length was 667 bp and the N50 (weighted median) was $988 \mathrm{bp}$. The assembly was qualitatively similar to a recently published de novo transcriptome assembled from multiple C. finmarchicus life stages (206,041 sequences, average length 997 bp, [26]). The larger average sequence length can be partially attributed to a difference in the minimum sequence length chosen for the two studies (200 bp in the present study, $300 \mathrm{bp}$ in the Lenz et al. [26] study).

\section{Transcriptome-wide analysis of differential gene expression}

Transcriptional profiling was conducted on samples collected on days 3 and 10 after the penultimate molt. 22,848 transcripts, corresponding to 7470 Trinity components were differentially expressed between these two days (Additional file 1: Table S1). Of these, one-third (7560 transcripts) returned positive blastx hits based on their similarity to other genes in the NCBI nonredundant (nr) database, and 28\% (6479 transcripts) were also associated with gene ontology (GO) terms (Additional file 2: Table S2). The GO terms most strongly enriched in the differentially expressed genes included terms related to remodeling of the cuticle (e.g., chitin metabolic process; structural constituent of cuticle), proteolysis (e.g., tyrosine catabolic process, peptidase activity), and hormonal signaling (e.g., steroid hormone mediated signaling pathway, retinoic acid receptor activity). The categories with the strongest enrichment in the differentially expressed genes are shown in Figure 3; complete results are given in Additional file 3: Table S3.

Of the 100 genes showing the strongest differential expression (lowest p-value), all were expressed at higher levels on day 10. Of these, 58 had no blast hit or only matched predicted proteins with no associated GO terms. A total of 30 genes could be grouped into a small number of categories: myosin heavy chain (14), structural components of cuticle (8), chitin-binding (4), and carbohydrate-binding groups (4). Decapod crustaceans undergo muscular atrophy in preparation for molting; however in American lobster (Homarus americanus), 




Figure 3 Gene ontology (GO) terms most strongly enriched (lowest p-value) in the set of differentially expressed genes. The complete set of statistically overrepresented terms is given in Additional file 3: Table S3.

this is accomplished with relatively small changes in myosin expression [29]. The very large changes observed in our study may indicate a distinct mechanism of moltassociated muscle remodeling in C. finmarchicus. The remaining 12 strongly up-regulated genes fell into 10 categories, including a Torso-like sequence that we selected for detailed expression profiling (see below). Of the genes showing higher expression on day 3, 76 of the 100 genes with the lowest $\mathrm{p}$-values had no blast hit or only matched predicted proteins with no associated GO terms. Among the 24 annotated genes, two were cuticle proteins, and the remaining genes were diverse, each associated with different GO terms. One of these genes was a fatty acid elongase that was similar to a gene we have measured previously (ELOV) and chose for more detailed expression profiling (see below).

Twelve genes were selected for detailed expression profiling in the time series study (Table 1) based on their (1) differential expression in the Illumina study, (2) expression patterns in our previous studies, and/or (3) likely role in reproduction or endocrine regulation of molting. Among these, ELOV (elongation of very long-chain fatty acids) and FABP (fatty acid binding protein) are presumed to function in lipid synthesis and transport; these genes also exhibit high expression in active C5 copepodids with small oil sacs [20]. Vtg is part of the vitellogenin family of lipoproteins that includes major egg yolk proteins (also called apolipocrustaceins in crustaceans) as well as proteins that play non-reproductive roles [30,31]. Fem-1 is an ankyrin domain-containing protein that is necessary for spermatogenesis in C. elegans [32]. Fem-1 function is poorly understood in other animal groups, although a Fem-1 homolog has also been suggested to play a role in mammalian prostate development [33]. Torso-like regulates embryonic patterning, developmental timing, body size, and ecdysone secretion [34,35]. ERR (estrogen-related receptor), EcR (ecdysone receptor), FTZ-F1 (FTZ factor 1), HR3, HR38a, HR38b, and HR78 (all named as hormone receptors, but without known ligands) are members of the nuclear receptor family of transcription factors. Nuclear receptors were preferentially selected for qPCR because genes in this family are known to regulate arthropod molting, and commonly show dynamic expression profiles $[13,17]$. Thus, we considered it likely that genes exhibiting modest differences in expression between the two time points sampled via Illumina might exhibit large changes at other times during the molt stage. The EcR sequence was previously described [20], while the other nuclear receptors were annotated according to a likelihood-based phylogenetic analysis that indicated strong support for grouping with homologs from Drosophila and Daphnia (Additional file 4: Figure S1). HR38a and HR38b appear to have resulted from a duplication of an ancestral HR38 sometime after the divergence of the copepod and cladoceran lineages (Additional file 4: Figure S1). 
Table 1 Sequences (Trinity "components") identified in the Illumina study and profiled using qPCR

\begin{tabular}{|c|c|c|c|c|c|c|}
\hline \multirow[b]{2}{*}{ Name } & \multirow[b]{2}{*}{ Component, accession } & \multicolumn{3}{|l|}{ Illumina } & \multicolumn{2}{|l|}{ qPCR } \\
\hline & & Log FC & Log CPM & FDR & Log FC & Range FC \\
\hline FABP & comp254629_c0 ES387222 & -2.24 & 8.57 & 4.55E-09 & -3.45 & 15.6 \\
\hline ELOV & comp267151_c1 ES387246 & -4.72 & 9.31 & 4.36E-16 & -4.74 & 30.0 \\
\hline HR78 & comp265637_c0 KJ026941 & -2.06 & 0.79 & $1.02 \mathrm{E}-04$ & -1.26 & 12.8 \\
\hline ERR & comp273411_c0 KJ026943 & -2.17 & 4.89 & $1.14 \mathrm{E}-08$ & -1.84 & 5.3 \\
\hline HR3 & comp264460_c0 KJ026938 & 3.21 & 4.48 & $2.59 \mathrm{E}-14$ & 3.84 & 64.2 \\
\hline HR38a & comp270260_c0 KJ026939 & 2.65 & 3.63 & $8.58 \mathrm{E}-12$ & 2.25 & 5.9 \\
\hline Vtg & comp274635_c1 KJ026944 & 3.20 & 8.14 & $3.45 \mathrm{E}-10$ & 1.15 & 597.9 \\
\hline Torso-like & comp266966_c0 KJ026945 & 9.26 & 7.40 & $1.19 \mathrm{e}-84$ & 8.24 & 1024.2 \\
\hline FTZ-F1 & comp268775_c0 KJ026942 & 3.25 & 5.97 & $3.05 \mathrm{E}-16$ & 4.25 & 32.0 \\
\hline HR38b & comp267178_c0 KJ026940 & 2.26 & 4.27 & $6.58 \mathrm{E}-10$ & 1.07 & 7.8 \\
\hline EcR & comp263662_c0 EF583877 & 1.10 & 3.13 & 0.39 & 1.06 & 3.4 \\
\hline Fem1 & comp269877_c0 KJ026947 & 4.43 & 7.08 & $1.67 \mathrm{E}-17$ & 1.33 & 7.6 \\
\hline
\end{tabular}

$\log _{2}$-transformed fold change (FC), $\log _{2}$-transformed counts per million (CPM), and false discovery rate (FDR) refer to the Illumina study comparing expression between 3 and 10 days after the penultimate molt. Log $_{2}$-transformed average FC between days 3 and 10 also reported for the qPCR study, as well as the untransformed FC between the minimum and maximum qPCR expression values observed throughout the C5 copepodid stage. Log-transformed FC is reported as a positive number for genes exhibiting greater expression later in the molt cycle (day 10) and a negative number for genes exhibiting greater expression earlier in the molt cycle (day 3).

Some of the genes (but not all) chosen for qPCR analysis were associated with statistically overrepresented GO terms: metal ion binding (ERR, FTZ-F1), retinoic acid receptor activity (HR38a, HR38b), steroid hormone receptor activity (HR38a, HR38b, EcR), retinoic acid receptor signaling pathway (HR38a, HR38b), steroid hormone mediated signaling pathway (HR38a, HR38b, EcR), and nuclear euchromatin (EcR). While GO enrichment analysis can be useful in identifying functionally related groups of co-expressed genes, automatic annotation is not without limitations, particularly for non-model organisms [36]. Some of these limitations can be seen in the above assignments. For example, all of the nuclear receptors that we profiled contain a DNA-binding domain that would be expected to form complexes with zinc ions; however, only a subset of the receptors was assigned with the "metal ion-binding" term.

\section{Detailed expression profiling}

The Illumina and qPCR results showed excellent agreement; each of the genes measured by both methods showed similar changes in expression between days 3 and $10\left(\mathrm{r}^{2}=0.894, \mathrm{p}<0.0001\right.$ for correlation of log-transformed fold changes between days 3 and 10 from the Illumina and qPCR studies; Table 1). Expression of FABP and ELOV peaked on day 3 and decreased thereafter by an average factor of 16 and 30, respectively (Figure 4a,b). Like FABP and ELOV, expression of HR78 and ERR also peaked early in the molt cycle and decreased steadily over time (Figure 4c,d). In contrast, HR3, HR38a, Vtg, and Torsolike each exhibited increasing trends in expression over time (Figure 4e-h). While expression of HR3, HR38a, and
Vtg increased fairly monotonically over time, Torso-like expression actually decreased over the first 7 days, increased dramatically by a factor of 768 between days 7 and 10, and remained high after day 10 (Figure 4h). FTZ-F1 and HR38b exhibited U-shaped expression patterns with minimum values observed during the middle of the molt cycle (Figure 4i,j). EcR was not differentially expressed within the Illumina study, and while variability among replicates was very high, there was a weak, inverse U-shaped, average expression pattern with maximum values observed during the middle of the molt cycle (Figure 4k). Finally, expression of Fem-1 showed a more complicated pattern of expression, remaining nearly constant over the first 8 days except for a transient peak in expression on day 6 and an increasing trend after day 8 (Figure 4l).

\section{Gene expression in copepods of known molt phase}

In animals of known molt stage, expression profiles were broadly consistent with those observed between the middle and late periods of the molt cycle during the time series study (Figure 5). ELOV expression decreased between pre- and post-apolysis samples $(\mathrm{p}=0.0093$; Figure $5 \mathrm{a})$ whereas expression of Torso-like, FTZ-F1, HR38b, EcR, and Fem-1 increased between pre- and post-apolysis samples $(\mathrm{p}<0.05$; Figure $5 \mathrm{~b}-\mathrm{f})$. Although variability among replicates was high and temporal patterns in Fem-1 and EcR were weak during the time series study (Figure $4 k, l$ ), these two genes exhibited the strongest differentiation between pre- and post-apolysis samples of all the examined genes (Fem-1: $\mathrm{t}=6.9, \mathrm{p}=0.0010$; EcR: $\mathrm{t}=4.4, \mathrm{p}=0.0073$ ). These results suggest that expression of Fem-1 and EcR is more closely synchronized with the molt cycle than with 

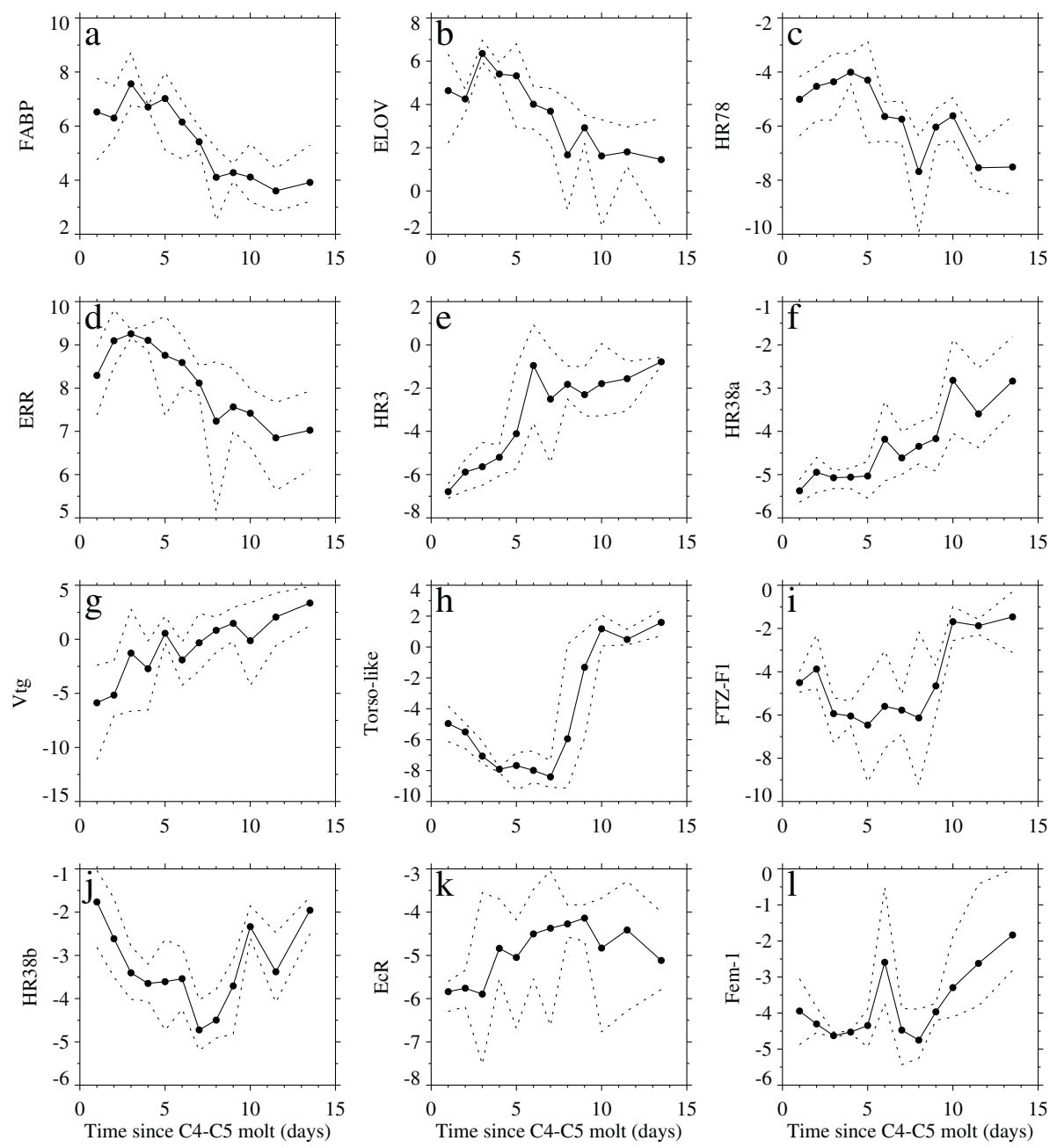

Figure 4 Average (filled circles) and minimum and maximum (dotted lines) of Calanus finmarchicus C5 copepodid gene expression measured via qPCR during the time series study. Each of the subpanels (a-I) represents the expression profile for an individual gene, which is specified on the $y$-axis. Average, minimum, and maximum values were computed for $n=3$ samples per day for days $1-10$; days $11-12$ and $13-14$ were combined to obtain $n=3$ samples for these combined 2-day periods (note that each sample consisted of 3 homogenized copepods). Expression was normalized by 4 housekeeping genes and $\log _{2}$ transformed. Negative numbers indicate lower expression than the geometric mean expression of the 4 housekeeping genes (see Methods for additional detail).

age within stage, and that variability in the timing of progression through the molt cycle (Figure 2b) caused high variability among replicates during the time series study of Fem-1 and EcR expression.

\section{Multivariate analysis of gene expression}

Principal component analysis (PCA) was conducted on expression of the 12 normalized genes for 36 samples (approximately 3 replicates per day in the time series study) to better understand overall patterns of expression of this set of genes (Figure 6). The first principal component explained half of the observed variability and captured the dominant linear trends with time for many of the genes: expression of HR3, HR38a, and Torso-like increased over time, while expression of HR78, FABP,
ELOV, and ERR decreased over time. The second principal component accounted for an additional $19 \%$ of the variability, and captured a U-shaped pattern over time observed in the expression of FTZF-1, HR38b, and EcR (where EcR has a roughly inverted $U$-shape). The average daily values of the first two principal component scores clustered into 3 time periods: early (days 1-5), middle (days 6-9) and late (days 10-14) (Figure 6c). These time periods, derived from the gene expression data, were consistent with our morphological observations. All C5 copepodids sampled during the early period had pre-apolysis jaws (Figure 2b), indicating they were in the early phase of the molt cycle. The middle period was characterized by the appearance of post-apolysis jaws (Figure 2b). Adults had only just begun to appear at the onset of the late period (Figure 2a), and 



Figure 5 Gene expression of pre- and post-apolysis Calanus finmarchicus C5 copepodids measured via qPCR 8 and 10 days after the penultimate molt. Each of the subpanels (a-f) indicates the expression level of an individual gene, which is specified on the $y$-axis. Data consist of $n=3$ samples for the pre-apolysis group and $n=4$ samples for the post-apolysis group (each sample consisted of 3 homogenized copepods of known molt stage). Expression was normalized by 4 housekeeping genes and $\log _{2}$ transformed. Negative numbers indicate lower expression than the geometric mean expression of the 4 housekeeping genes (see Methods for additional detail). Results shown for only those genes with significantly different expression between pre- and post-apolysis (Student's t-test, $\mathrm{p}<0.05$ ).

during this time, nearly all C5 copepodids had differentiated gonads (Figure $2 \mathrm{~b}$ ).

\section{Gene expression marker of late progression toward the terminal molt}

Determining within-stage progress toward the terminal molt was of particular interest to us, so we sought to develop a gene expression indicator that strongly discriminated between the early (days $1-5$ ) and late periods (days 10-14) within the molt cycle. The expression ratio of all possible pairs of un-normalized genes from the time-series study ( $\mathrm{n}=12$ genes) were first calculated and $\log _{2}$ transformed. Then the Student's t-statistic comparing the ratio between the early period ( $\mathrm{n}=15$ samples) and late period ( $\mathrm{n}=9$ samples) was calculated for each gene pair. The gene pair with the highest t-statistic was considered the best discriminator between the early and late periods. Of the 66 possible gene expression ratios, the ratio of Torso-like to HR38b had, by far, the highest t-statistic $(\mathrm{t}=24.1, \mathrm{p}<0.0001$; note that $\mathrm{p}<\alpha$, where $\alpha=0.05 / 66=$ 0.00076, the Bonferroni adjusted cutoff value; Figure 7a). During the early period, HR38b expression was an average 12.2 times higher than that of Torso-like, and during the late period, Torso-like expression was an average 12.5 times higher than that of HR38b (Figure 7a). The middle period (days 6-9) was characterized by a dramatic change in the ratio (Figure $7 \mathrm{~b}$ ). While Torso-like alone provides good discrimination between the early and late periods (Figure 4h), the ratio of Torso-like to HR38b provides better discrimination because the ratio is less variable during the early period when expression levels of both genes decrease simultaneously.

\section{Discussion}

The lipids stored in the C. finmarchicus oil sac provide energy to support basal metabolism during diapause, as well as molting and reproduction. The present study provides, to our knowledge, the first dynamic profile of oil sac volume in Calanus spp. C5 copepodids progressing toward the terminal molt. Oil sac volume is strongly correlated with wax ester content in C. finmarchicus C5 copepodids [4]. While triglycerides are typically present in relatively small amounts, they appear to serve as a labile energy source that is utilized both during short periods of starvation and during egg production $[4,37]$. Thus, it will be of interest to profile wax ester and triglyceride content in future studies of C. finmarchicus development, as well as to identify molecular markers associated with synthesis and utilization of each lipid type. During our study, oil sac volume increased over time, presumably to fuel molting, reproduction and adult metabolic needs [5-7], and genes associated with lipid accumulation (FABP and ELOV) peaked on day 3 and decreased afterward. In a field study of $C$. finmarchicus $C 5$ copepodids, we showed that expression of FABP and ELOV was highest in active animals with small oil sacs [20]. If these copepods were early developing $\mathrm{C} 5$ copepodids, then their high FABP and ELOV expression is consistent with the high FABP and ELOV 

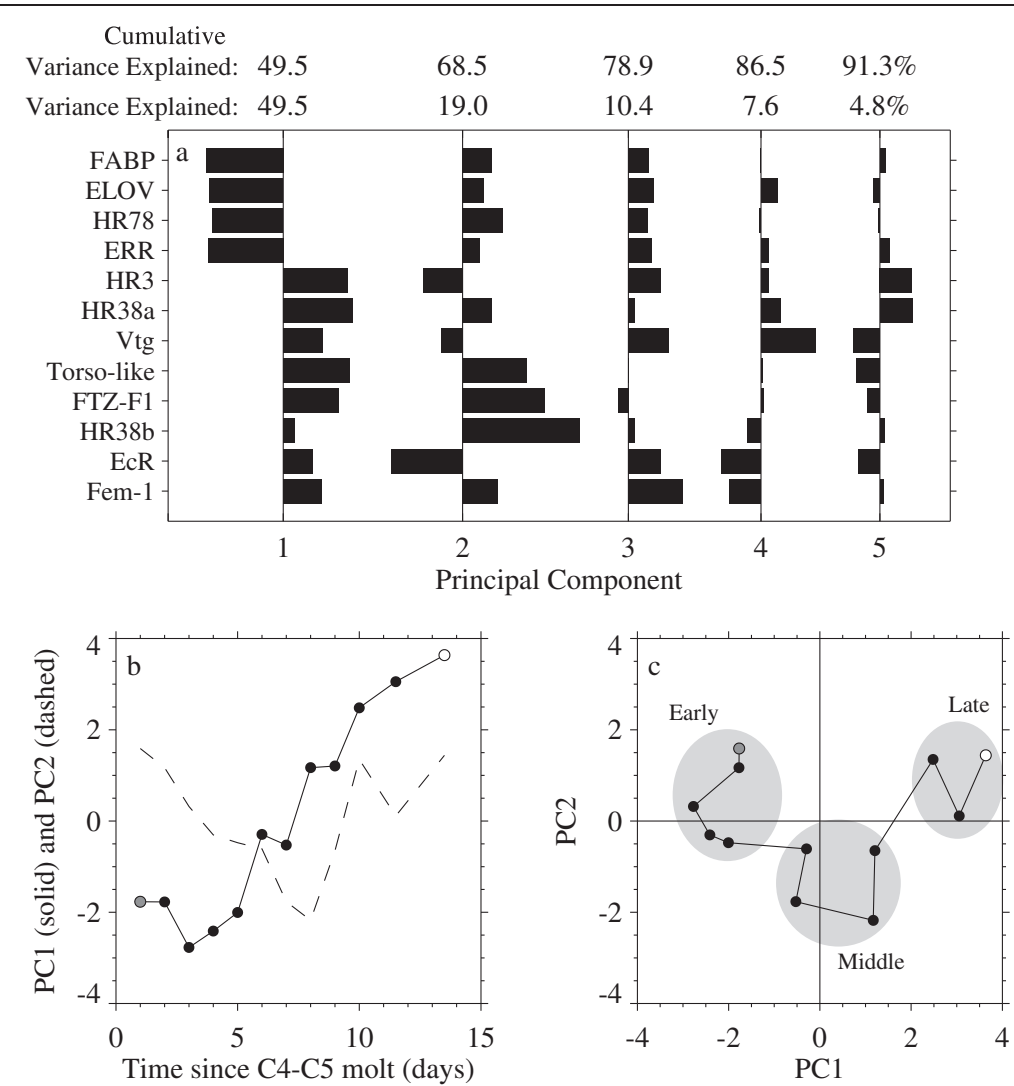

Figure 6 Multivariate analysis distinguishes three periods of gene expression within the molt cycle. Results of principal component (PC) analysis of gene expression data from the time series study: (a) eigenvectors for the first 5 PCs, (b) time series of average PC scores for the first (filled circles) and second (dashed line) PC, and (c) scatterplot of average PC scores for the first 2 PCs. Gray-filled and open circles in (b) and (c) indicate the start and end of the time series, respectively. Gray ellipses in (c) indicate early (days 1-5), middle (days 6-9), and late (days 10-14) periods.

expression observed in the early developing C5 copepodids from our culture study. In this previous study [20], we assumed that changes in FABP and ELOV expression were associated with diapause preparation, but the present study shows that changes in the expression of these genes are more generally associated with lipid accumulation, which is necessary both for diapause and progression toward the terminal molt. ERR expression also peaked on day 3 and decreased afterward. While the specific function of this nuclear receptor in C. finmarchicus is unknown, ERR is an important regulator of energetic homeostasis and lipid metabolism [38,39].

During progression through the C5 stage, the proportion of copepodids with differentiated gonads increased. While nearly half (44\%) of the copepodids with differentiated gonads possessed testes, only $25 \%$ of the emerged
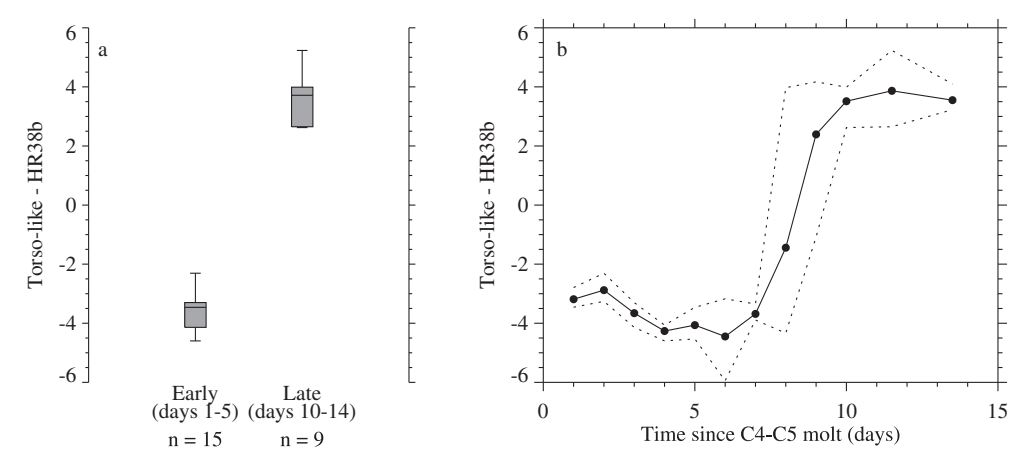

Figure 7 High Torso-like to HR38b expression indicates late molt stage. (a) Log 2 -transformed ratio of Torso-like to HR38b expression during the early (days 1-5) and late (days 10-14) periods of the time series study. (b) Average (filled circles) and minimum and maximum (dotted lines) of $\log _{2}$-transformed Torso-like to HR38b expression ratio. 
adults were male. Differences in the sex ratio of wild copepod populations are frequently attributed to differential mortality (e.g., [40]), but mortality was extremely low in the culture study. Sex ratio in Calanus spp. can be influenced by food availability, food quality, population density and other environmental factors, and cultured populations are usually biased toward females ([41] and references therein). Because we sampled most of the copepodids prior to the terminal molt, we cannot be sure what proportion of the population would have eventually emerged as adults. One possibility is that males develop more slowly, which is weakly supported by our data (Figure 2a). A second intriguing possibility is that sex change accounts for the observed difference in sex ratio, as has been previously suggested for $C$. finmarchicus (reviewed by [42]).

We profiled the expression of three genes, Vtg, Fem-1, and Torso-like, each of which is associated with reproductive development in other animals. We identified several Vtg-like transcripts, most of which did not exhibit differential expression between days 3 and 10. The Vtg transcript profiled in this study increased over time in the C5 stage, but decreased in both male and female adults (adult expression not shown). This differs from Vtg expression profiles described in other copepods in which expression is highest in adult females where it plays a role in egg yolk production $[43,44]$. Closely-related genes (e.g., Crossveinless d) serve non-reproductive developmental roles in insects [31]. While we do not know the specific role of the Vtg-like gene we have profiled in C. finmarchicus, we consider it likely that it serves a developmental role unrelated to egg yolk production. Fem-1 expression exhibited high variability among replicates, weak temporal patterns, and a strong increase after apolysis. This gene helps to regulate spermatogenesis in C. elegans [32], so the weak temporal variability observed within the culture may be due to sexually dimorphic expression. The strong discrimination between pre- and post-apolysis animals of similar time in stage may indicate a transitory peak in expression not resolved in the time series study. Torso-like has been studied most extensively in Drosophila, in which it is transmitted from the ovary to the oocyte to regulate development of the head and tail regions of the resulting embryo; however, this role of Torso-like embryonic patterning is likely a derived function restricted to a few insect lineages [45]. While the function of Torso-like is unknown in C. finmarchicus, the large dynamic range in expression with a maximum in post-apolysis animals is consistent with a conserved role in regulation of molting hormones, as has been shown in insects: [34,35].

EcR did not exhibit differential expression between days 3 and 10 in the Illumina study. In the time series study, EcR expression was greatest during the middle period, but temporal trends were weak. This weak temporal pattern can be partially attributed to asynchrony within the molt stage obscuring developmental changes, as evidenced by the strongly differentiated expression of EcR before and after apolysis (Figure 5e). In insects, EcR regulates expression of other nuclear receptors including HR78 and HR3, and HR3 in turn induces expression of FTZ-F1 (reviewed by [13]). In C. finmarchicus, several other nuclear receptors (HR38b, HR3, FTZ-F1) exhibited dynamic profiles during the time series study. The dynamic expression profiles of these genes may by driven primarily by changes in ecdysteroid concentrations rather than changes in the expression of EcR. In insects, HR78 and HR38 both oppose EcR signaling [46,47]. In our study, HR78 expression was highest early in the molt cycle, with peak expression on day 4. This preceded the peak in EcR expression observed on day 9 , which may have prevented premature activation of ecdysis pathways. Of the two HR38 genes in C. finmarchicus, HR38a increased over time, and HR38b exhibited a U-shaped pattern similar to FTZ-F1 that was broadly in opposition to EcR. Expression patterns of HR38b and FTZ-F1 were closely associated with molt progression, exhibiting a strong increase after apolysis (Figure 5c,d). HR3 expression generally increased over time and showed a transient peak on day 7. Among copepods collected on days 8 and 10, HR3 expression was highly variable prior to apolysis (not shown), which is consistent with an ephemeral peak in HR3 expression shortly before apolysis.

We identified several genes that we expect will be useful for identifying wild C5 copepodids that are in the late stages of preparation for the terminal molt. The copepods used in this study were all taken from a long-term continuous culture in which the animals are reared at a constant temperature, with a reliable food supply, without any exposure to predators, and at higher densities than they generally occur in nature. For reasons that are not known, Calanus spp. does not undergo diapause in culture, and we do not understand in what other ways the physiology and corresponding gene expression of cultured and wild C5 copepodids differ. Therefore, it will be necessary to compare the gene expression profiles observed in our culture study with wild populations that are preparing for the terminal molt. We anticipate that Torsolike and HR38b, whose ratio changes dramatically during C5 development, may prove especially useful for identifying copepods nearing the terminal molt. The lipid accumulation hypothesis of diapause initiation [48-50] predicts that copepods that skip diapause and proceed directly to the terminal molt have lower lipid reserves than those preparing for diapause. With a biomarker that predicts late molt stage, the lipid volume of copepods preparing for the terminal molt can be directly examined in the field. Moreover, this biomarker can be used to identify animals in the field that are not actively preparing for the terminal molt, 
of which some will be preparing for diapause. Within this subpopulation of $\mathrm{C} 5 \mathrm{~s}$, we anticipate that additional transcriptional profiling and gene expression studies will identify genes directly associated with preparation for diapause during the C5 stage. The development of robust gene expression biomarkers of these two developmental pathways will ultimately enable novel studies of the intrinsic and extrinsic factors that govern diapause initiation and termination in Calanus finmarchicus.

\section{Conclusions}

This study provides the first dynamic profiles of gene expression through a copepod molt cycle. In addition to processes of growth and ecdysis that are common to all molt stages, the C. finmarchicus C5 stage is also characterized by lipid storage and gonad development. These processes are interrelated in the sense that lipid stores provide energy to fuel ecdysis and reproduction. Broadly, we have observed that FABP and ELOV expression is high early in the C5 stage, and decreases over time as lipids accumulate. Several nuclear receptors exhibited dynamic expression profiles consistent with a signaling cascade triggered by ecdysteroids. We measured, for the first time, gene expression in copepods of known molt stage and identified genes that exhibit dramatic changes in expression during apolysis. These include genes with presumed roles in lipid synthesis, molt regulation and gonad development, which is consistent with a coupling of these processes. Finally, we identified the ratio of Torso-like to HR38b as a biomarker that strongly differentiates between early and late development within the C5 copepodid stage.

\section{Methods}

\section{Culturing}

Copepods were collected from a long-term continuous culture of C. finmarchicus maintained at the NTNU/SINTEF SeaLab facility in Trondheim, Norway [19]. Copepods were reared at $8-10^{\circ} \mathrm{C}$ in $280-1$ polyester containers through which filtered natural seawater from nearby Trondheimsfjord (collected at $70 \mathrm{~m}$ depth) was continuously passed. All copepods were fed a diet of Dunaliella tertiolecta, Isochrysis galbana, and Rhodomonas baltica at levels $>150 \mu \mathrm{g} \mathrm{C}^{-1}$. During May 2012, 1900 stage C4 copepodids were removed from the culture and transferred to 2.5-1 containers (40 individuals per container, 48 containers). Every day for 9 consecutive days, each copepod was gently removed with a $17 \mathrm{~cm}^{3}$ ladle, transferred to a clear plastic spoon, and examined under a stereomicroscope. If an individual had molted from C4 to C5 during the preceding 24 hours, it was transferred to a new 2.5-l container and not examined again until its sample date (see below). A total of 34 2.5-1 containers were filled with 35-47 (average of 38) C5 copepodids, resulting in 1306 individuals for whom the date of the penultimate ( $\mathrm{C} 4$ to $\mathrm{C} 5)$ molt was known to within a day.

\section{Sampling}

Containers with C5 copepodids were assigned randomly to particular sample dates to allow data collection on each day after the penultimate molt, including days 1-18 for a time series study and days 3 and 10 for Illumina-based transcriptional profiling (see below). All animals from a single container with the same penultimate molt date were sampled simultaneously. Individuals were removed from the container with a ladle, staged on a depression slide, photographed alive with a Canon EOS-20D camera attached to a Zeiss Stemi 2000C stereomicroscope, and preserved either in RNAlater (Ambion) for quantitative polymerase chain reaction ( $\mathrm{qPCR}$ ) or transcriptional profiling, or in $10 \%$ buffered formalin for assessment of jaw phase or gonad stage. For the time series study, individuals from each container were randomly assigned to one of three analysis types: jaw phase ( $\mathrm{n}=10$ copepods), gonad stage ( $n=10$ copepods), or qPCR analysis ( $n=15$ copepods). These sample sizes could not be maintained during the last few days of the time series study when the occurrence of C5 copepodids was low (because many molted into adults prior to sampling), so data from these last days were combined for all analyses. For qPCR and Illumina analyses, replicates of 3 copepods each were preserved in RNAlater.

\section{Morphometrics, jaw phase, and gonads}

Prosome length and width and oil sac volume of each sampled copepod were estimated with measurements obtained from digital photographs of the live animals (after Tarrant et al. [20]). Measured lengths were calibrated with repeated photographs of a stage micrometer taken during sampling. Jaw phase was assessed by extracting the mandible under a stereomicroscope, mounting it in glycerine under a cover slip, and photographing the gnathobase under a Zeiss Axiovert 40 inverted compound microscope outfitted with differential interference contrast optics and a Zeiss AxioCam ICc1 camera. Jaws were classified after Miller et al. [11] and Crain and Miller [51]. Apolysis, the process by which the epidermis separates from the cuticle, is an important milestone in molt preparation; we therefore refer to pre-apolysis copepodids as those with jaws in the post-molt, late post-molt, interphase, or columnar cell tooth-forming phases, and postapolysis copepodids are those with jaws in any of the other late tooth-forming phases (apolysis, tooth molds, silicified teeth, or extricated teeth). To assess gonad stage, C5 copepodids were stained by passing them through 5 baths of seawater serially diluted with deionized water $(100,75,50$, $25,12.5 \%$ seawater for 20 minutes each), a deionized water bath of 3\% Fast Green (20 minutes), 3 baths of deionized 
water, and 5 baths of increasing ethanol concentration (15 minutes in 15, 40, and 75\% ethanol, 37 minutes each in 95 and $100 \%$ ethanol); final preservation was in terpineol. Gonads were viewed with an inverted compound microscope and classified according to Crain and Miller [52]. Differentiated gonads are defined as those from which an individual's gender can be determined (i.e., developing ovaries and testes).

\section{RNA extraction and library preparation}

Total RNA was extracted from copepods using the Aurum Fatty and Fibrous Tissue Kit (Bio-Rad). RNA purity and yield were assessed using a Nanodrop spectrophotometer. For the time series study, on-column DNase digestion was used to remove genomic DNA, and RNA quality was assessed using denaturing agarose gels. For the Illumina study, RNA quality was assessed using a Bioanalyzer. Samples were submitted to the Genomic Services Laboratory at HudsonAlpha (Huntsville, AL), where libraries were synthesized using Illumina TruSeq reagents. Four libraries were constructed from each of days 3 and 10, and each library was prepared using total RNA extracted and pooled from enough copepods to yield at least $4 \mu \mathrm{g}$ of RNA (3-6 copepods). For transcriptome assembly, an additional library was constructed from equal amounts of RNA pooled from each of these eight samples $(2 \mu \mathrm{g}$ total $)$ along with $2 \mu \mathrm{g}$ of RNA from wild C5 C. finmarchicus collected in Trondheimsfjord, Norway during May 2012. RNA from wild copepods was included in the library to facilitate future field-based transcriptional profiling studies.

\section{Illumina-based sequencing and data analysis}

For transcriptome assembly, samples were sequenced with 100 base pair (bp) paired-end reads with a depth equivalent to $1 / 2$-lane on an Illumina HighSeq2000. For expression profiling, samples were sequenced with $50 \mathrm{bp}$ paired-end reads with a depth equivalent to $1 / 4$-lane per sample. Adapter sequences and bases with low quality scores $(<$ phred 20) were removed using Trimmomatic [53] in paired-end mode. After trimming, reads at least $50 \mathrm{bp}$ long were retained for assembly. A transcriptome was assembled de novo using Trinity version r2012-06-08 [54] with default parameters. Transcripts were annotated using Blast2Go [55] with a threshold e-value of $10^{-6}$. Postassembly analysis was conducted using scripts bundled within the Trinity package. Reads were mapped to the reference transcriptome and quantified using the RSEM software package [56]. Read counts were TMM-normalized (trimmed mean of M-values) to account for differences in library size [57] and then FPKM-normalized (fragments per feature kilobase per million reads mapped) to account for differences in transcript length. Transcripts exhibiting differential expression between the two time points were identified using EdgeR software [58]. Default parameters were used, including a $\mathrm{p}$-value cutoff for false discovery rate (FDR) of 0.001 and a minimum 4-fold change in expression. Statistically enriched gene ontology (GO) terms were identified using the GOseq R Bioconductor package [59].

\section{Cloning and phylogenetic analysis}

Portions of transcripts of interest (672-1313 bp) were amplified by PCR (as in [20]), both to verify the assembled sequence and to provide standards for qPCR. All primers are provided in Additional file 5: Table S4. Amplicons were cloned into pGEM-T Easy (Promega) and sequenced. To improve the provisional annotation of several transcripts within the nuclear receptor superfamily, the cloned C. finmarchicus sequences were aligned with the complete nuclear receptor sets from human, Drosophila melanogaster and Daphnia pulex, excluding the atypically structured nuclear receptors (Family 0). Amino acid sequences were aligned using ClustalW, and maximum likelihood analysis was conducted with RAxML v7.0.4 [60] using the JTT + I + G + F model.

\section{Quantitative PCR (qPCR)}

Complementary DNA (cDNA) was synthesized from $450 \mathrm{ng}$ of total RNA in a 20- $\mu$ l reaction using the Iscript cDNA synthesis kit (Bio-Rad). The 20- $\mu$ l reaction was diluted with $30 \mu \mathrm{l}$ of molecular biology grade water such that each microliter of diluted cDNA corresponded to 9 ng of total RNA. qPCR was performed using SsoFast EvaGreen Supermix (Bio-Rad) on an iCycler iQ Real-Time PCR detection system (Bio-Rad). Primer sequences for ELOV, FABP and EcR were previously described [20], and all other primer sequences are given in Additional file 5: Table S4. Standards were prepared from a serially diluted plasmid containing the amplicon. All samples and standards were run in duplicate wells. The $20-\mu \mathrm{l}$ qPCR reaction contained $10 \mu \mathrm{l}$ master mix, $8 \mu \mathrm{l}$ molecular biology grade water, $1 \mu$ diluted cDNA and $1 \mu \mathrm{l} 10 \mathrm{nM}$ primers. Cycling parameters were: $95^{\circ} \mathrm{C}$ for 2 min followed by 40 cycles of $95^{\circ} \mathrm{C}$ for $5 \mathrm{~s}$ and $63^{\circ} \mathrm{C}$ for $10 \mathrm{~s}$. After cycling, the products were subjected to melt curve analysis to ensure that only a single specific product was amplified.

Transcript expression was calculated relative to the standard curve and $\log _{2}$-transformed. Expression was further adjusted by subtracting a normalization factor equal to the geometric mean of 4 genes that exhibited relatively constant levels of expression after [61]. Three of these normalizer genes were selected from the Illumina data to have moderate expression levels and a low coefficient of variation among samples (TSG: KJ026946 tumor susceptibility gene 101 protein-like, UBX: KJ026948 UBX domaincontaining protein 6-like, and SNP: KJ026949 snurportin 1-like). The fourth normalizer gene (EF-1 $\alpha$ : ES414812, similar to elongation factor 1 alpha) has been used in 
previous qPCR studies of C. finmarchicus [19] and exhibited stable expression in our study.

Gene expression was measured with qPCR on days 116 of the time series study. Three biological replicates were measured on days 1-10, 2 replicates were measured on days 11,13 , and 16 , and 1 replicate on days 12,14 , and 15. Results from days 11-12 and days 13-14 were combined in all figures. Results from days 15 and 16 were excluded from further analysis because those days exceeded the median C5 stage duration of the culture.

Because molt stage progression was not synchronous within the culture (see Results), we used RNAlater-preserved samples collected on days 8 and 10 to simultaneously assess jaw phase and measure gene expression in the same individual C5 copepodids. Mandibles were extracted and examined, and after jaw phase was determined, the rest of the body was grouped with copepods that had similar jaw phases. Each replicate sample for qPCR consisted of total RNA extracted and pooled from 3 copepods with either (1) jaw phases occurring immediately before apolysis (interphase or columnar cell tooth forming phases) or (2) jaw phases occurring after apolysis (apolysis, tooth molds, silicified teeth, or extricated teeth). We analyzed 3 and 4 replicates each for pre- and post-apolysis jaw phases, respectively.

\section{Availability of supporting data}

The cloned DNA sequences (Genbank accessions KJ026938KJ026947), raw Illumina sequences, and Transcriptome Shotgun Assembly are archived at NCBI (NCBI BioProject: PRJNA231164 [GenBank:PRJNA231164], Transcriptome Shotgun Assembly DDBJ/EMBL/GenBank Accession GBFB00000000. The version described in this paper is GBFB01000000): Other data sets supporting the results of this article are included within the article and its additional files.

\section{Additional files}

Additional file 1: Table S1. Tab-delimited file containing normalized counts (FPKM) and RSEM statistical analysis of Trinity components differentially expressed between days 3 and 10. Column 1: Comp Name, the name of the differentially expressed Trinity component. Column 2: $\log F C$, the $\log _{2}$-transformed fold change in expression; positive numbers indicate higher expression on day 10 of the time series relative to day 3 . Column 3: $\log C P M, \log _{2}$-transformed counts per million. Column 4: $\mathrm{p}$-value, indicating significance of difference in expression between days 3 and 10. Column 5: FDR, false discovery rate. Columns 6-9: normalized expression values for biological replicates collected on day 3 (EC1.genes-EC4.genes). Columns 10-13: normalized expression values for biological replicates collected on day 10 (LC1.genes-LC4. genes). Column 14: \# annotated seqs: the number of transcripts ("segs") corresponding to a given line (component) that are annotated in Additional file 2: Table S2. Columns 15-22: the blast2GO-based annotation based on the first corresponding sequence present in Additional file 2: Table S2 (if any).

Additional file 2: Table S2. Tab-delimited file containing annotation of transcripts with a positive blastx hit (e-value $<10^{-6}$ ) that were differentially expressed between days 3 and 10. Column 1: Trinity transcript name. Column 2: Sequence description. Column 3: Sequence length. Column 4: Number of blast hits. Column 5: Lowest e-value of significant blast hit. Column 6: Mean percent similarity. Column 7: Number of associated GO terms. Column 8: List of associated GO terms.

Additional file 3: Table S3. Microsoft Excel file containing the complete list of gene ontology (GO) terms that are statistically overrepresented in the set of genes differentially expressed between days 3 and 10 .

Additional file 4: Figure S1. Maximum likelihood tree of nuclear receptors from human (Homo sapien; Hs), Drosophila melanogaster (Dm) and Daphnia pulex (Dp) with newly-identified Calanus finmarchicus (Cf) nuclear receptors shown in red. Nuclear receptors are typically grouped into 6 families (a seventh family with contains genes with atypical structure is not shown), some of which are further divided into subfamilies [62]; these designations are indicated on the right side of the figure. Accession numbers for $C$. finmarchicus sequences are given in Table 1. All other accession numbers are given in Additional file 1 of [63] Tree is unrooted. Values to the right of nodes indicate percent of 1,000 bootstraps. Scale bar at bottom indicates the number of amino acid substitutions per site. Trees were visualized using FigTree v1.1.2 (http://tree.bio.ed.ac.uk/software/figtree/).

Additional file 5: Table S4. Word document. Primers used for cloning of plasmid standards and for quantitative PCR.

\section{Abbreviations}

Bp: Base-pair; C4 and C5: Fourth and fifth copepodid stage, respectively; cDNA: Complementary DNA; CPM: Counts per million; DNA: Deoxyribonucleic acid; EcR: Ecdysone receptor; EF-1a: Elongation factor 1 alpha; ELOV: Elongation of very long-chain fatty acids; ERR: Estrogen-related receptor; FABP: Fatty acid binding protein; FDR: False discovery rate; FPKM: Fragments per feature kilobase per million reads mapped; FTZ-F1: Fushi tarazu transcription factor 1; GO: Gene ontology; HR: Hormone receptor (e.g., HR38: hormone receptor 38); nr: Non-redundant (database); PC(A): Principle component (analysis); PCR: Polymerase chain reaction; qPCR: Quantitative PCR; RNA: Ribonucleic acid; RXR: Retinoid-x-receptor; SNP: Snurportin; TMM: Trimmed mean of M-values; TSG: Tumor suppressor gene; Vtg: Vitellogenin.

\section{Competing interests}

The authors declare that they have no competing interests.

\section{Authors' contributions}

AMT and MFB conceived of the study, analyzed data and wrote the article. AMT conducted Illumina analysis and GPCR assays. MFB conducted morphological and statistical analyses. AMT, MFB and DA conducted the culture study. BHH, DA, TN and AO contributed to the study design, prepared culture and sampling infrastructure, and facilitated sampling during the culture study. All authors reviewed and contributed to the final manuscript. All authors read and approved the final manuscript.

\section{Acknowledgements}

This work was supported by grant number OCE-1132567 from the National Science Foundation to MFB and AMT. Additional supported was provided by WHOI Early Career Scientist Awards provided to MFB and AMT. High-performance computing was provided through the Extreme Science and Engineering Discovery Environment (XSEDE), which was supported by National Science Foundation grant number OCl-1053575. We thank Nadine S.J. Lysiak for logistical and sampling support, and Amalia Aruda Almada, Morgan Rubanow and Emily Conklin for laboratory assistance. Amy Maas provided bioinformatics advice. We also thank three anonymous reviewers for constructive comments.

\section{Author details}

${ }^{1}$ Biology Department, Woods Hole Oceanographic Institution, 45 Water Street, Woods Hole, MA 02543, USA. ${ }^{2}$ SINTEF Materials and Chemistry, Environmental Technology, N-7465 Trondheim, Norway. ${ }^{3}$ BioTrix, N-7022 Trondheim, Norway. ${ }^{4}$ Department of Biology, Norwegian University of Science and Technology, N-7491 Trondheim, Norway.

Received: 23 July 2014 Accepted: 1 December 2014

Published online: 16 December 2014 
References

1. Saumweber WJ, Durbin EG: Estimating potential diapause duration in Calanus finmarchicus. Deep-Sea Res Pt II 2006, 53:2597-2617.

2. Hirche HJ: Diapause in the marine copepod, Calanus finmarchicus - a review. Ophelia 1996, 44:129-143.

3. Marshall S, Orr A: The Biology of a Marine Copepod, Calanus finmarchicus (Gunnerus). Edinburgh: Oliver \& Boyd, London; 1955:188.

4. Miller CB, Morgan CA, Prahl FG, Sparrow MA: Storage lipids of the copepod Calanus finmarchicus from Georges Bank and the Gulf of Maine. Limnol Oceanogr 1998, 43:488-497.

5. Rey-Rassat C, Irigoien X, Harris R, Carlotti F: Energetic cost of gonad development in Calanus finmarchicus and C. helgolandicus. Mar Ecol Prog Ser 2002, 238:301-306.

6. Sargent JR, Falk-Petersen S: The lipid biochemistry of calanoid copepods. Hydrobiologia 1988, 167/168:101-114.

7. Hirche H-J: The reproductive biology of the marine copepod, Calanus finmarchicus - a review. Ophelia 1996, 44:111-128.

8. Svetlichny LS, Hubareva ES: The energetics of Calanus euxinus: locomotion, filtration of food and specific dynamic action. J Plankton Res 2005, 27:671-682

9. Miller C, Crain J, Morgan C: Oil storage variability in Calanus finmarchicus ICES J Mar Sci 2000, 57:1786-1799.

10. Tande KS, Hopkins CCE: Ecological investigations of the zooplankton community of Balsfjorden, Northern Norway: The genital system in Calanus finmarchicus and the role of gonad development in overwintering strategy. Mar Biol 1981, 63:159-164.

11. Miller CB, Nelson DM, Weiss C, Soeldner AH: Morphogenesis of opal teeth in calanoid copepods. Mar Biol 1990, 106:91-101.

12. Chang ES, Mykles DL: Regulation of crustacean molting: a review and our perspectives. Gen Comp Endocrinol 2011, 172:323-330.

13. Ou Q, King-Jones K: What goes up must come down: transcription factors have their say in making ecdysone pulses. Curr Top Dev Biol 2013, 103:35-71.

14. Hwang D-S, Lee J-S, Lee K-W, Rhee J-S, Han J, Lee J, Park G, Lee Y-M, Lee J-S: Cloning and expression of ecdysone receptor (EcR) from the intertidal copepod Tigriopus japonicus. Comp Biochem Physiol C Toxicol Pharmacol 2010, 151:303-312

15. Asazuma $\mathrm{H}$, Nagata $\mathrm{S}$, Kono $\mathrm{M}$, Nagasawa $\mathrm{H}$ : Molecular cloning and expression analysis of ecdysone receptor and retinoid $X$ receptor from the kuruma prawn, Marsupenaeus japonicus. Comp Biochem Physiol B Biochem Mol Biol 2007, 148:139-150.

16. Durica D, Wu X, Anilkumar G, Hopkins PM, Chung AC-K: Characterization of crab EcR and RXR homologs and expression during limb regeneration and oocyte maturation. Mol Cell Endocrinol 2002, 189:59-76.

17. Hannas BR, LeBlanc GA: Expression and ecydsteroid responsiveness of the nuclear receptors HR3 and E75 in the crustacean Daphnia magna. Mol Cell Endocrinol 2010, 315:208-218.

18. Johnson C: Ecdysteroids in the oceanic copepod Calanus pacificus: variation during molt cycle and change associated with diapause. Mar Ecol Prog Ser 2003, 257:159-165.

19. Hansen BH, Altin D, Hessen KM, Dahl U, Breitholtz M, Nordtug T, Olsen AJ: Expression of ecdysteroid and cytochrome P450 enzymes during lipid turnover and reproduction in Calanus finmarchicus (Crustacea: Copepoda). Gen Comp Endocrinol 2008, 158:115-121.

20. Tarrant A, Baumgartner M, Verslycke T, Johnson C: Differential gene expression in diapausing and active Calanus finmarchicus (Copepoda). Mar Ecol Prog Ser 2008, 355:193-207.

21. Clark KAJ, Brierley AS, Pond DW, Smith VJ: Changes in seasonal expression patterns of ecdysone receptor, retinoid $\mathrm{X}$ receptor and an A-type allatostatin in the copepod, Calanus finmarchicus, in a sea loch environment: an investigation of possible mediators of diapause. Gen Comp Endocrinol 2013, 189:66-73.

22. Seear P, Tarling G, Burns G, Goodall-Copestake W, Gaten E, Ozkaya O, Rosato E: Differential gene expression during the moult cycle of Antarctic krill (Euphausia superba). BMC Genomics 2010, 11:582.

23. Kuballa A, Merritt D, Elizur A: Gene expression profiling of cuticular proteins across the moult cycle of the crab Portunus pelagicus. BMC Biol 2007, 5:45

24. Ventura T, Manor R, Aflalo ED, Chalifa-Caspi V, Weil S, Sharabi O, Sagi A Post-embryonic transcriptomes of the prawn Macrobrachium rosenbergii: multigenic succession through metamorphosis. PLoS One 2013, 8:e55322.
25. Ning J, Wang M, Li C, Sun S: Transcriptome sequencing and de novo analysis of the copepod Calanus sinicus using 454 GS FLX. PLoS One 2013, 8:e63741.

26. Lenz PH, Roncalli V, Hassert RP, Wu LS, Cieslak MC, Hartline DK, Christie AE: De novo assembly of a transcriptome for Calanus finmarchicus (Crustacea, Copepoda) - The dominant zooplanker of the North Atlantic Ocean. PLoS One 2014, 9:e88589.

27. Christie AE, Fontanilla TM, Roncalli V, Cieslak MC, Lenz PH: Identification and developmental expression of the enzymes responsible for dopamine, histamine, octamine and serotonin biosynthesis in the copepod crustacean Calanus finmarchicus. Gen Comp Endocrinol 2013, 195:28-39.

28. Christie AE, Roncalli V, Wu L-S, Ganote CL, Doak T, Lenz PH: Peptidergic signaling in Calanus finmarchicus (Crustacea, Copepoda): In silico identification of putative peptide homones and their receptors using a de novo assembled transcriptome. Gen Comp Endocrinol 2013, 187:117-135.

29. Medler S, Brown KJ, Chang ES, Mykles DL: Eyestalk ablation has little effect on actin and myosin heavy chain expression in adult lobster skeletal muscles. Biol Bull 2005, 208:127-137.

30. Avarre J-C, Lubzens E, Bapin PJ: Apolipocrustacein, formerly vitellogenin, is the major egg yolk precursor protein in decapod crustaceans and is homologous to insect apolipophorin II/I and vertebrate apolipoprotein B. BMC Evol Biol 2007, 7:3.

31. Chen J, Honeyager SM, Schleede J, Avanesov A, Laughon A, Blair SS: Crossveinless $d$ is a vitellogenin-like lipoprotein that binds BMPs and HSPGs, and is required for normal BMP signaling in the Drosophila wing. Development 2012, 139:2170-2176.

32. Doniach T, Hodgkin J: A sex-determining gene, fem-1, required for both male and hermaphrodite development in Caenorhabditis elegans. Dev Biol 1984, 106:223-235

33. Wang X, Desai N, Hu YP, Price SM, Abate-Shen C, Shen MM: Mouse Fem1b interacts with the Nkx3.1 homeoprotein and is required for proper male secondary sexual development. Dev Dyn 2008, 237:2963-2972.

34. Grillo M, Furriols M, de Miguel C, Franch-Marro X, Casanova J: Conserved and divergent elements in Torso RTK activtion in Drosophila development. Sci Rep 2012, 2:762.

35. Johnson TK, Crossman T, Foote KA, Henstridge MA, Saligari MJ, Beadle LF, Herr A, Whisstock JC, Warr CG: Torso-like functions independently of Torso to regulate Drosophila growth and developmental timing. Proc Natl Acad Sci U S A 2013, 110:14688-14692.

36. Primmer CR, Papakostas S, Leder EH, Davis MJ, Ragan MA: Annotated genes and nonanotated genomes: cross-species use of Gene Ontology in ecology and evolution research. Mol Ecol 2013, 22:3216-3241.

37. Hakanson JL: The long and short term feeding condition in field-caught Calanus pacificus, as determined from the lipid content. Limnol Oceanogr 1984, 29:794-804.

38. Tennessen JM, Baker KD, Lam G, Evans J, Thummel CS: The Drosophila estrogen-related receptor directs a metabolic switch that supports developmental growth. Cell Metab 2011, 13:139-148.

39. Giguere V: Transcriptional control of energy homeostasis by the estrogen-related receptors. Endocr Rev 2008, 29:677-696.

40. Kiorboe T: Sex, sex-ratios, and the dynamics of pelagic copepod populations. Oecologia 2006, 148:40-50

41. Irigoien X, Obermüller B, Head RN, Harris RP, Rey C, Hansen BW, Hygum BH, Heath MR, Durbin EG: The effect of food on the determination of sex ratio in Calanus spp.: evidence from experimental studies and field data. ICES J Mar Sci 2000, 57:1752-1763.

42. Gusmão LFM, McKinnon AD: Sex ratios, intersexuality and sex change in copepods. J Plankton Res 2009, 31:1101-1117.

43. Dalvin S, Frost P, Loeffen P, Skern-Mauritzen RS, Baban J, Rønnestad I, Nilsen F: Characterization of two vitellogenins in the salmon louse Lepeophtheirus salmonis: molecular, functional and evolutional analysis. Dis Aquat Organ 2011, 94:211-224.

44. Lee K-W, Hwang D-S, Rhee J-S, Ki J-S, Park HG, Ryu J-C, Raisuddin S, Lee J-S: Molecular cloning, phylogenetic analysis and developmental expression of a vitellogenin $(\mathrm{Vg})$ gene from the intertidal copepod Tigriopus japonicus. Comp Biochem Physiol B Biochem Mol Biol 2008, 150:395-402.

45. Duncan EJ, Benton MA, Dearden PK: Canonical terminal patterning is an evolutionary novelty. Dev Biol 2013, 377:245-261. 
46. Zhu J, Miura K, Chen L, Raikhel A: AHR38, a homolog of NGFI-B, inhibits formation of the functional ecdysteroid receptor in the mosquito Aedes aegypti. EMBO J 2000, 19:253-262.

47. Fisk GJ, Thummel CS: The DHR78 nuclear receptor is required for ecdysteroid signaling during the onset of Drosophila metamorphosis. Cell 1998, 93:543-555.

48. Irigoien $X$ : Some ideas about the role of lipids in the life cycle of Calanus finmarchicus. J Plankton Res 2004, 26:259-263.

49. Rey-Rassat C, Irigoien X, Harris R, Head R, Carlotti F: Growth and development of Calanus helgolandicus reared in the laboratory. Mar Ecol Prog Ser 2002, 238:125-138.

50. Maps F, Plourde S, Zakardjian B: Control of dormancy by lipid metabolism in Calanus finmarchicus: a population test model. Mar Ecol Prog Ser 2010, 403:165-180.

51. Crain JA, Miller CB: Effects of starvation on intermolt development in Calanus finmarchicus copepodites: a comparison between theoretical models and field studies. Deep-Sea Res Pt II 2001, 48:551-566.

52. Crain J, Miller C: Detection of sex and sex ratio in Calanus finmarchicus early stage fifth copepodites. ICES J Mar Sci 2000, 57:1773-1779.

53. Lohse M, Bolger AM, Nagel A, Fernie AR, Lunn JE, Stitt M, Usadel B: RobiNA: a user-friendly integrated software solution for RNA-Seq-based transcriptomics. Nucleic Acids Res 2012, 40:W622-W627.

54. Grabherr MG, Haas BJ, Yassour M, Levin JZ, Thompson DA, Amit I, Adiconis X, Fan L, Raychowdhury R, Zeng Q, Chen Z, Mauceli E, Hacohen N, Gnirke A, Rhind N, di Palma F, Birren BW, Nusbaum C, Lindblad-Toh K, Friedman N, Regev A: Full-length transcriptome assembly of RNA-Seq data without a reference transcriptome. Nature Biotechnol 2011, 29:644-652.

55. Conesa A, Gotz S, Garcia-Gomez JM, Terol J, Talon M, Robles M: Blast2GO: a universal tool for annotation, visualization and analysis in functional genomics research. Bioinformatics 2005, 21:3674-3676.

56. Li B, Dewey C: RSEM: accurate transcript quantification from RNA-Seq data with or without a reference genome. BMC Bioinformatics 2011, 12:323.

57. Robinson MD, Oshlack A: A scaling normalization method for differential expression analysis of RNA-seq data. Genome Biol 2010, 11:R25.

58. Robinson MD, McCarthy DJ, Smyth GK: edgeR: a Bioconductor package for differential expression analysis of digital gene expression data. Bioinformatics 2010, 26:139-140.

59. Young MD, Wakefield MJ, Smyth GK, Oshlack A: Gene ontology analysis for RNA-seq: accounting for selection bias. Genome Biol 2010, 11:R14.

60. Stamatakis A: RAxML-VI-HPC: maximum likelihood-based phylogenetic analyses with thousands of taxa and mixed models. Bioinformatics 2006, 22:2688-2690

61. Vandesompele J, De Preter K, Pattyn F, Poppe B, Van Roy N, De Paepe A, Speleman F: Accurate normalization of real-time quantitative RT-PCR data by geometric averaging of multiple internal control genes. Genome Biol 2002, 3:RESEARCH0034.

62. Nuclear Receptors Nomenclature Committee: A unified nomenclature system for the nuclear receptor superfamily. Cell 1999, 97:161-163.

63. Thomson SA, Baldwin WS, Wang YH, Kwon G, Leblanc GA: Annotation, phylogenetics, and expression of the nuclear receptors in Daphnia pulex. BMC Genomics 2009, 10:500.

\section{doi:10.1186/s12983-014-0091-8}

Cite this article as: Tarrant et al:: Transcriptional profiling of reproductive development, lipid storage and molting throughout the last juvenile stage of the marine copepod Calanus finmarchicus. Frontiers in Zoology 2014 11:91.

\section{Submit your next manuscript to BioMed Central and take full advantage of:}

- Convenient online submission

- Thorough peer review

- No space constraints or color figure charges

- Immediate publication on acceptance

- Inclusion in PubMed, CAS, Scopus and Google Scholar

- Research which is freely available for redistribution 